\title{
OPEN Stress-sensing in the human greying hair follicle: Ataxia Telangiectasia Mutated (ATM) depletion in hair bulb melanocytes in canities-prone scalp
}

\author{
Stephen K. Sikkink ${ }^{1 \bowtie}$, Solene Mine ${ }^{2}$, Olga Freis ${ }^{2}$, Louis Danoux ${ }^{2}$ \& Desmond J. Tobin ${ }^{1,3 凶}$
}

Canities (or hair greying) is an age-linked loss of the natural pigment called melanin from hair. While the specific cause(s) underlying the loss of melanogenically-active melanocytes from the anagen hair bulbs of affected human scalp remains unclear, oxidative stress sensing appears to be a key factor involved. In this study, we examined the follicular melanin unit in variably pigmented follicles from the aging human scalp of healthy individuals (22-70 years). Over 20 markers were selected within the following categories: melanocyte-specific, apoptosis, cell cycle, DNA repair/damage, senescence and oxidative stress. As expected, a reduction in melanocyte-specific markers in proportion to the extent of canities was observed. A major finding of our study was the intense and highly specific nuclear expression of Ataxia Telangiectasia Mutated (ATM) protein within melanocytes in anagen hair follicle bulbs. ATM is a serine/threonine protein kinase that is recruited and activated by DNA doublestrand breaks and functions as an important sensor of reactive oxygen species (ROS) in human cells. The incidence and expression level of ATM correlated with pigmentary status in canities-affected hair follicles. Moreover, increased staining of the redox-associated markers 8-OHdG, GADD45 and GP-1 were also detected within isolated bulbar melanocytes, although this change was not clearly associated with donor age or canities extent. Surprisingly, we were unable to detect any specific change in the expression of other markers of oxidative stress, senescence or DNA damage/repair in the canities-affected melanocytes compared to surrounding bulbar keratinocytes. By contrast, several markers showed distinct expression of markers for oxidative stress and apoptosis/differentiation in the inner root sheath (IRS) as well as other parts of the hair follicle. Using our in vitro model of primary human scalp hair follicle melanocytes, we showed that ATM expression increased after incubation with the pro-oxidant hydrogen peroxide $\left(\mathrm{H}_{2} \mathrm{O}_{2}\right)$. In addition, this ATM increase was prevented by pre-incubation of cells with antioxidants. The relationship between ATM and redox stress sensing was further evidenced as we observed that the inhibition of ATM expression by chemical inhibition promoted the loss of melanocyte viability induced by oxidative stress. Taken together these new findings illustrate the key role of ATM in the protection of human hair follicle melanocytes from oxidative stress/damage within the human scalp hair bulb. In conclusion, these results highlight the remarkable complexity and role of redox sensing in the status of human hair follicle growth, differentiation and pigmentation.

Canities or hair greying is associated with the aging process and characterised by new growth of unpigmented hair fibre within hair follicles ${ }^{1}$. Under normal conditions hair follicle melanocytes actively produce and transfer melanin to pre-cortical keratinocytes during the anagen growth phase of the hair follicle cycle, leading to a fully pigmented hair fibre. During subsequent rounds of hair cycling it is thought that transient amplifying

${ }^{1}$ Centre for Skin Sciences, School of Life Sciences, University of Bradford, Richmond Rd., Bradford BD7 1DP, West Yorkshire, UK. ${ }^{2}$ BASF Beauty Care Solutions France S.A.S., Pulnoy, France. ${ }^{3}$ The Charles Institute of Dermatology, School of Medicine, University College Dublin, Dublin 4, Ireland. ${ }^{\varpi}$ email: s.k.sikkink@bradford.ac.uk; desmond.tobin@ucd.ie 
melanocytes, derived from a pool of stem-cell like melanoblasts located in the bulge region (niche), repopulate and pigment the newly formed hair follicle ${ }^{2}$. Work by Nishimura and colleagues confirmed the location of the melanocyte stem cell niche in murine hair follicles to the lower portion of the bulge region where melanoblasts can repeatedly migrate out of, divide and repopulate the niche again ${ }^{3-6}$. Once these cells move to the hair bulb they differentiate into mature melanocytes and transfer pigment into the cortex keratinocytes. Despite extensive studies of the biochemical and cellular pathways that influence pigmentation, the exact molecular mechanisms that lead to hair greying in the human anagen hair follicle are still relatively unclear ${ }^{7,8}$. Studies (albeit predominantly in mice) have pointed to a number of factors including increased oxidative stress in the hair follicle ${ }^{9}$, depletion of melanoblast stem cells from the niche ${ }^{10}$, apoptosis of differentiated matrix melanocyte in the hair bulb $^{11}$ and DNA damage repair (DDR) abnormalities, that all may contribute in part to hair greying ${ }^{12}$. The reader is directed to an excellent recent review on the topic by O'Sullivan and colleagues ${ }^{13}$.

Oxidative stress is caused by an imbalance in pro- and anti-oxidant systems in cells and tissues and can increase damage to all biomolecules including proteins and $\mathrm{DNA}^{14-17}$. Uncontrolled levels of reactive oxygen species (ROS) have been implicated in aging ${ }^{18}$ and in a variety of pathological conditions like dementia ${ }^{19,20}$ and various cancers $^{21-23}$. In melanocytes, ROS can be produced from external sources such as chemical/mechanical environmental stressors ${ }^{24}$ or through intrinsic cellular processes such as melanogenesis in response to ultra-violet (UV) radiation ${ }^{25-28}$. Usually cells (including melanocytes) have distinct overlapping mechanisms for coping with ROS/antioxidant imbalance from multiple sources to prevent cellular damage ${ }^{29-33}$. The transcription factor nuclear erythroid 2-related factor (NRF2) is a major component of the cells response to oxidative stress ${ }^{34-36}$ and is expressed at very high levels in epidermal cells ${ }^{37}$. NRF2 provides a protective effect in melanocytes in response to both UV irradiation and oxidative stress ${ }^{30,31}$, through transcriptional upregulation of the antioxidant response element (ARE) genes including Superoxide dismutase-1 (SOD-1), Glutathione peroxidase-1 (GP-1), Glutathione reductase-1 (GR-1), Catalase and Heme oxygenase-1 (HO-1) ${ }^{38-40}$. Studies in melanocytes have demonstrated that levels of HO-1 and its interaction with NFR2 are quickly upregulated in response to ROS ${ }^{30,31,41}$. A study by Haslam, et al., in human ex vivo hair follicles, also showed that NRF2 was crucial during $\mathrm{H}_{2} \mathrm{O}_{2}$ induced oxidative stress in co-ordinating specific anti-oxidant response elements including GR-1 and HO- $1^{42}$.

Aside from antioxidant metabolism and regulation in response to elevated ROS, cells also recruit components of the DNA damage response (DDR) pathway to cope with the potential damaging effect of free radicals on $\mathrm{DNA}^{29,43}$. A central component in this response is the Ataxia-Telangiectasia mutated (ATM) gene, a serine/ threonine kinase, which is activated in response to DNA double strand breaks ${ }^{44}$. ATM naturally exists as a resting inactive dimer which is auto-phosphorylated into an active monomeric form that interacts with the MRE11/ RAD50/NBS1 (MRN) complex at the site of strand breaks, co-ordinating DNA repair ${ }^{45,46}$. ATM also phosphorylates multiple downstream targets (notably including, p53, $\gamma-\mathrm{H} 2 \mathrm{AX}, \mathrm{CHK} 1$ and $\mathrm{CHK} 2$ ) that are also involved in apoptosis, cell cycle regulation and DNA repair ${ }^{47-49}$. The mechanism during oxidative stress is different to the DDR response, in that ATM forms a disulphide linked stable dimer activated independently of MRN and DNA damage ${ }^{50,51}$. Despite being a predominantly nuclear protein, several studies have indicated that during elevated ROS that ATM may translocate through the nuclear membrane to interact with cytosolic proteins localised in the peroxisome, mitochondria and microsome ${ }^{52-54}$. The importance of ATM in the cellular response to oxidative stress can be seen by investigating its role in the autosomal recessive disorder ataxia telangiectasia (A-T), after which ATM is named ${ }^{55}$. A-T patients lack fully functioning ATM and are predisposed to a range of malignancies, radiation sensitivity, immunological and neurological disorder ${ }^{56}$ caused by abnormalities in the cells response to DNA repair and elevated ROS levels particularly in neurons ${ }^{57}$. Studies in ATM-deficient mouse models have also shown similar abnormalities ${ }^{58}$. Interestingly ATM deficient patients can sometimes present with early aging phenotypes including canities or with the pigment disorder vitiligo ${ }^{56}$ and mice lacking ATM can also display coat and tail pigmentation abnormalities particularly after genotoxic insult ${ }^{59}$. Inomata et al. investigated the effects of ATM knockout on murine hair follicles and described niche depletion of melanocyte stem cells from the bulge region of the hair follicle in response to genotoxic stress ${ }^{10}$. ATM deficiency caused sensitization and early differentiation of melanoblasts leading to depletion from the stem cell niche which caused depigmentation of the follicle in subsequent hair cycles. Arck et al., also proposed the 'free radical theory of greying' which described increased apoptosis, reduced oxidative stress protection and increased mitochondrial DNA damage in hair follicles leading to depletion of melanocytes and greying hair ${ }^{60}$.

Despite studies investigating stress, ROS or pigmentation markers in both pigmented and canities affected hair follicles, information on the collective status, expression and distribution of selected cell cycle, DNA damage, apoptosis and ROS metabolising anti-oxidant markers in aging human scalp follicles is limited. In this study we have analysed the protein expression of over 20 markers of cell cycle, DNA damage, apoptosis, senescence and oxidative stress in hair bulb melanocytes and in the wider growth scalp hair follicle in normal healthy individuals across six decades. Here we show distinct nuclear expression of ATM within (surviving) melanocytes in canitiesaffected hair bulbs of the hair follicle, the frequency of which correlated with hair follicle pigmentary status. We found infrequent expression of other markers of senescence, DNA damage/repair and oxidative stress specifically within the bulbar melanocytes. A prominent feature of this study was the strong expression of markers for apoptosis/(terminal) differentiation and ROS activity for the anagen hair follicle's inner root sheath (IRS). In vitro analysis of cultured human hair follicle melanocytes showed that ATM is a marker of oxidative stress in these cells. ATM appears to play a role in protecting human hair follicle melanocytes from oxidative stress/damage, and maintenance of its expression within the follicle microenvironment along with other redox markers may be important for hair bulb melanocyte survival in canities-prone scalp hair follicles. 


\begin{abstract}
Methods
Tissue collection and approval. Research was carried out according to local University of Bradford (UoB) good research practice guidelines. Healthy normal human haired scalp (age range 22-70 years) was sourced from elective (cosmetic) plastic surgery. Tissue was obtained with regulated informed consent from all individuals by the UoB Ethical Tissue Bank (an ethically approved human research tissue bank, licensed by the Human Tissue Authority (HTA), Licence number: 12191) with approval from the National Research Ethics Service (NRES) Committee Yorkshire \& The Humber-Leeds East (approval number 17/YH/0086). Tissue was placed in transport media (DMEM containing L-glutamine, $10 \% \mathrm{FCS}, 5 \times$ Pen/Strep, $3 \times$ antifungal) immediately after removal. Samples were cleaned in wash solution (phosphate buffered saline (PBS) containing $5 \times$ Pen/Strep with antimycotic/antifungal) and hair was shaved off close to the epidermis.
\end{abstract}

Double immunohistochemistry of scalp tissue. This assay was conducted as described previously and adapted to the antibodies used ${ }^{61}$. Briefly, ten micron sections were air-dried onto slides for at least $1 \mathrm{~h}$ prior to fixing in ice-cold acetone for $10 \mathrm{~min}$ at $-20^{\circ} \mathrm{C}$. Non-specific antibody binding was reduced by incubating in $10 \%$ donkey serum (Sigma-Aldrich, UK) diluted in PBS for at least $30 \mathrm{~min}$, followed by simultaneous incubation in primary antibodies (a melanocyte marker with a target antibody; see Supplementary table 1) diluted in PBS containing $1 \%$ donkey serum overnight at $4{ }^{\circ} \mathrm{C}$. After washing sessions in PBS for $3 \times 10 \mathrm{~min}$, these were then incubated in donkey Alexa-488 and 594 conjugated secondary antibodies (1:100 dilutions, Thermofisher, $\mathrm{UK})$ for $1 \mathrm{~h}$ at RT. After washing the sections were mounted for confocal microscopy under sealed coverslips in fluorescent mounting medium containing DAPI nuclear stain (VectorLabs, UK). Images were collected using the $365 \mathrm{~nm}$ (DAPI), $488 \mathrm{~nm}$ (Alexa-488) and $543 \mathrm{~nm}$ (Alexa-594) channels on a Zeiss LSM confocal microscope by sequential line scanning. Images were processed using the LSM confocal image browser software (Zeiss, UK) and ImageJ (freeware).

Isolation of human scalp hair follicle melanocytes. Isolation and purification of hair follicle melanocytes (HFMs) from scalp hairs was carried out as originally previously described in Tobin, et al. ${ }^{62}$ with modifications ${ }^{63}$. Cell lineage identity was confirmed by GP100 and TRP-1 expression. Melanocytes were maintained in full 2:1 melanocyte growth media (2 parts minimal essential medium (MEM) supplemented with $1 \%$ foetal bovine serum (FBS), $1 \%$ nonessential amino acids, $100 \mu \mathrm{g} / \mathrm{ml}$ Primocin, $2 \mathrm{mM}$ Glutamax, $5 \mathrm{ng} / \mathrm{ml}$ basic fibroblast growth factor, and $5 \mathrm{ng} / \mathrm{ml}$ endothelin-1 (Sigma, Dorset, UK) mixed with 1 part keratinocyte serumfree medium (K-SFM) supplemented with $25 \mu \mathrm{g} / \mathrm{ml}$ bovine pituitary extract (BPE), $0.2 \mathrm{ng} / \mathrm{ml} \mathrm{rEGF}, 100 \mu \mathrm{g} /$ $\mathrm{ml}$ Primocin (antibiotic), and $2 \mathrm{mM}$ Glutamax in humidified incubators at $37{ }^{\circ} \mathrm{C}$ with $5 \% \mathrm{CO}_{2}$ unless stated otherwise.

Treatment of hair follicle melanocytes in culture. Prior to treatment, primary HFMs were incubated for $24 \mathrm{~h}$ in 'starved' 2:1 melanocyte media (2:1 melanocyte media minus $1 \%$ FBS and BPE). All treatments were carried out in starved 2:1 melanocyte media for the duration of experiments. Pro-oxidants: fresh hydrogen peroxide (Sigma, UK) solution was prepared as a $10 \mathrm{mM}$ stock solution immediately before use then diluted to the required concentration. Menadione (Sigma, UK) was dissolved in DMSO to $100 \mathrm{mM}$ then diluted to $100 \mu \mathrm{M}$ in media immediately prior to use. Antioxidants: Vitamin E and Quercetin (VitE/Q; Sigma, UK) were dissolved in water $(1 \mathrm{mM})$ and DMSO $(10 \mathrm{mM})$ respectively before combining to a final concentration of $10 \mu \mathrm{M}$ (Vitamin E) and $1 \mu \mathrm{M}$ (Quercetin) in media. Cells were pre-incubated with VitE/Q for $1 \mathrm{~h}$ prior to ROS induction. The ATM specific kinase inhibitor KU60019 (Tocris, UK) was dissolved in DMSO to $100 \mathrm{mM}$ then diluted to $5 \mu \mathrm{M}$ directly into media. Cells were pre-incubated in KU60019 for $1 \mathrm{~h}$ prior to ROS induction.

Quantification of ATM expression. Cultured hair follicle melanocytes were seeded into 8-well chamber slides $(\sim 10,000$ cells/well $)$ and left to attach for at least $24 \mathrm{~h}$, fixed in ice-cold methanol for $10 \mathrm{~min}$, and incubated with blocking buffer of $10 \%$ donkey serum (Sigma-Aldrich, UK) for at least $30 \mathrm{~min}$. After washing, this was followed by incubation in anti-ATM primary antibody [Y170] (Abcam, Cat\# ab32420) diluted 1:100 overnight at $4{ }^{\circ} \mathrm{C}$ and then incubated in donkey Alexa-488 conjugated secondary antibodies $(1: 100$ dilution, Invitrogen Molecular Probes, UK) for $1 \mathrm{~h}$ at RT. The slides were mounted under medium containing DAPI (VectorLabs, $\mathrm{UK}$ ) for confocal microscopy. Images were collected using the $365 \mathrm{~nm}$ (DAPI) and $488 \mathrm{~nm}$ (Alexa-488) channels on a Zeiss LSM confocal microscope by sequential line scanning. Images were processed using the LSM confocal image browser software (Zeiss, UK) and ImageJ (freeware).

Western blot analysis. Primary HFMs were seeded into 6-well plates ( 500,000 per well) and left to attach overnight. Prior to treatment, cells were incubated in starved media for $24 \mathrm{~h}(2: 1$ melanocyte media minus FCS and BPE). After treatment, media was removed and cells rinsed in PBS before lysis with $200 \mu$ ice-cold RIPA buffer (Sigma, UK) containing protease inhibitors (Complete EDTA protease inhibitor tablets; Roche, UK) and phosphatase inhibitors (phosphatase inhibitor tablets; Pierce, UK). Cell lysates were sonicated briefly for $15 \mathrm{~s}$ then protein concentration measured using the Microplate BCA. Protein Assay Determination Kit-Reducing Agent Compatible (Pierce, UK). Lysates were diluted in $2 \times$ Laemelli SDS sample buffer containing $50 \mathrm{mM}$ DTT to equal concentration then $\sim 10 \mu \mathrm{g}$ of protein electrophoresed through NuPage 3-8\% Tris-Acetate gels (Thermofisher Scientific) alongside Kaleidoscope (Bio-Rad, UK) and HiMark (Invitrogen, UK) protein standards. Protein was transferred to PVDF membrane (Mini Trans-blot Turbo Transfer Pack) using the Trans-blot Turbo module at $2.5 \mathrm{~A}$ constant ( $25 \mathrm{~V})$ for $30 \mathrm{~min}$. PVDF membranes were cut to size and blocked in $5 \%(\mathrm{w} / \mathrm{v})$ non-fat milk powder dissolved in TBS-T (TBS-Tween $20(0.01 \% \mathrm{v} / \mathrm{v}))$ for at least $1 \mathrm{~h}$ at room temperature (RT). 
Membranes were incubated in either Abcam Cat\# ab32420 Rabbit anti-ATM [Y170] antibody diluted 1:4000 in $5 \%$ milk/TBS-T overnight at $4{ }^{\circ} \mathrm{C}$, then rinsed in TBS-T. Membranes were then incubated for $30 \mathrm{~min}$ at RT in HRP-conjugated secondary antibody (Santa Cruz Biotechnology, Inc, USA) diluted in 5\% milk or BSA in TBS-T. Separated membranes containing WesternC marker were incubated in Streptavidin HRP-conjugated label $(1: 20,000)$ and secondary antibody only. Excess secondary antibody and Streptavidin-HRP was removed by washing in 4 changes of TBS-T. Cut membranes were pieced back together and incubated in Clarity ECL detection reagent (Bio-Rad, UK) for $5 \mathrm{~min}$ then imaged using the ChemidocMP imaging system (Bio-rad, UK). Protein bands were quantified by densitometry using Image Lab v4.1 software (Bio-Rad, UK). For Catalase and GP-1 Western blotting samples were prepared as described earlier, however proteins were electrophoresed through Bio-Rad Any kD mini-TGX PAGE gels alongside Kaleidoscope and Western C markers (Bio-Rad, UK), then transferred to PVDF using a Turbo Transfer blotter $(2.5 \mathrm{~mA}, 25 \mathrm{~V}$ constant for $10 \mathrm{~min})$. Membranes were blocked as earlier in 5\% Milk/TBS-T then probed overnight with mouse anti-Catalase primary antibody (Sigma \#C0979, diluted 1:1000 in 5\% milk/TBS-T) at $4{ }^{\circ} \mathrm{C}$ then rinsed in TBS-T buffer. Membranes were then incubated for $30 \mathrm{~min}$ at RT in HRP-conjugated secondary antibody (Santa Cruz, Biotechnology, Inc, USA) diluted in 5\% milk in TBS-T and imaged as described previously. Where necessary, membranes were stripped using Restore reagent (Thermofisher, UK) then reprobed for the housekeeping gene GAPDH (1:2000 Cat\# MCA4740, BioRad, UK) as a loading control.

Cell viability test. Primary HFMs were seeded into 96-well plates at a density of $1 \times 10^{4}$ cells/well $(n=12)$ in full 2:1 Melanocyte media. Cells were incubated at $37^{\circ} \mathrm{C}$ with $5 \% \mathrm{CO}_{2}$ overnight to attach to plates, rinsed in PBS, then placed in starved media overnight before treatment. Treatments were prepared immediately prior to addition with a final dilution into starved media then added to cells. DMSO vehicle (basal) controls $(0.00005 \%$ $\mathrm{v} / \mathrm{v}$ ) were also used in parallel. Following incubation, cells were rinsed in PBS then incubated with WST-1 reagent (diluted 1:10 into fresh starved media (Roche, UK)) and incubated at $37^{\circ} \mathrm{C}$ for $4 \mathrm{~h}$ in a cell culture incubator according to manufacturer's instructions. Plates were scanned for absorbance at $\mathrm{A}_{450 \mathrm{~nm}}$ on a Tecan M200 plate reader using a reference wavelength of $A_{690 \mathrm{~nm}}$. Results were analysed using Magellan 6.0 software (Tecan, Germany). Mean absorbance relating to cell viability was calculated then plotted on a bar chart (Graphpad Prism v6.0).

Statistics. Data were expressed as mean \pm SEM. Error bars also show SEM. Differences between data were evaluated by Student's t test or ANOVA where stated after testing the data normality using Graphpad Prism v6.0.

\section{Results}

Human scalp from multiple normal healthy donors was assessed for the expression of canities-relevant modulators of melanocyte phenotype using a panel of 23 different antibodies by immunofluorescence. Antibodies were directed against proteins implicated in key pathways such as apoptosis, cell cycle regulation, senescence, DNA repair/damage and oxidative stress. Double-staining was performed using a melanocyte-specific marker to investigate colocalization in bulbar HFM. Brightfield imaging was used in parallel to monitor the pigmentation status (melanin level) of each stained hair bulb.

Expression of melanocyte specific markers in greying human hair follicles. The correlation between the pigmentation status and the melanocyte-specific markers (GP100, Tyrosinase related protein-1 (TRP-1) and Tyrosinase (TYR) was evaluated in human scalp hair bulbs. The first observation was that scalp tissues from donors aged from 22 to 70 years old, contained variably pigmented follicles. Multiple donors had fully pigmented follicles co-located with intermediary to weakly/non- pigmented hair follicles (data not shown). Comparison of melanocytes staining with melanin content of hair bulbs showed the expected gradual decrease in melanocyte labelling from fully pigmented to weakly/non-pigmented hair bulbs (Fig. 1 and supplementary figure 1). The intensity and the distribution level of the staining of TRP-1 and GP100 was higher in the hair follicle melanocytes of fully pigmented follicles, sporadic in melanocytes with reduced pigmentation and lacking in weakly pigmented/white hair follicles (Fig. 1). The intensity of staining of TYR was also correlated to the pigmentation status of the hair bulb. However, the protein exhibited lower levels of expression and distribution in the hair bulb melanocytes compared to those of TRP-1 and GP100. For instance, TYR staining was markedly reduced in the melanocytes of hair follicles with mild or moderate canities, despite strong TRP-1 expression in the same hair follicle (see supplementary figure 1). The lack of full overlapping between the three-melanocyte lineage-specific markers suggests differential labelling of melanocyte populations. The melanocyte-specific marker TRP-2 was also investigated. However, the hair bulb of anagen hair follicles lacked TRP-2 expression as previously reported ${ }^{64}$.

ATM staining correlates with pigmentary status in hair follicles. A major finding of the immunofluorescence study on scalp tissues was that in addition to the melanocyte specific markers, another protein appears to be strongly related to the hair bulb melanocytes and their pigmentary status. Expression of the DNArepair coordinator and oxidative stress sensor ATM was exclusively restricted to hair follicle melanocytes (i.e. was not expressed in follicular keratinocytes and fibroblasts) with a pattern that correlated with pigmentary status of the hair follicle within the hair bulb (Fig. 2). Heavily pigmented hair follicles showed strong nuclear ATM colocalisation within bulbar melanocyte nuclei. In hair follicles with reduced overall pigmentation, hair bulb melanocytes displayed variably reduced expression or absent ATM expression. ATM expression was completely absent in white hair follicles without pigmented cells (i.e. full canities). It was also noted that frequent strong ATM nuclear staining was colocalised within the nuclei of GP100 positive melanocytes and occasional 


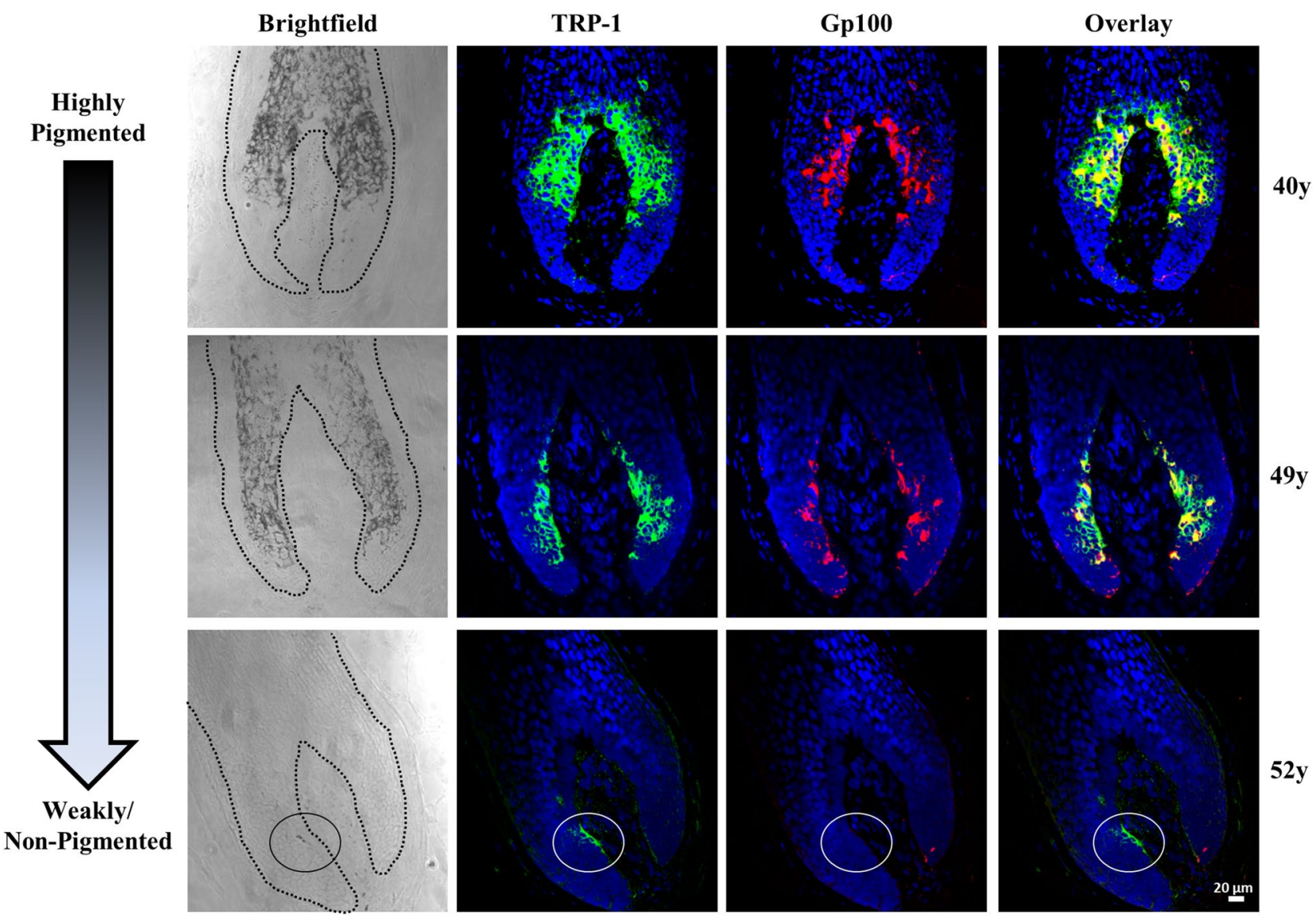

Figure 1. Expression of melanocyte markers GP100 and TRP-1 is reduced in proportion to canities extent. Double IF of scalp tissue with TRP-1 (green channel) \& GP100 (red channel) shows strong staining of both markers with a gradual decrease in melanocyte labelling from highly pigmented to weakly non-pigmented grey hair follicles. Melanocyte marker expression was proportional to the melanin content observed in brightfield images (left panels; hair follicle outline is indicated with black dashed line). Circles in lower panels show the last remaining TRP-1 positive/GP100 negative staining of isolated melanocyte(s) localised to a small region of the inner hair bulb with near complete (fully grey) canities (which is still pigmented in the brightfield image). DAPI nuclear stain is shown in blue channel. Scale bar $=20 \mu \mathrm{m}$. Donor age is indicated on the right.

basal keratinocytes in the UVR exposed epidermis of multiple scalp samples. Nuclear ATM staining was not detected within dermal fibroblasts (supplementary figure 2), and although some cytoplasmic expression was visible. Among the biomarkers implicated in cell cycle, DNA damage/repair, apoptosis, senescence and oxidative stress, only ATM was consistently expressed in hair follicle melanocytes in situ and correlated to the pigmentary status of the hair bulb. By contrast, only occasional colocalisation with isolated bulbar melanocytes was detected for GP-1, 8-OHdG and GADD45; however, their expression pattern or level did not correlate strongly with overall pigmentary status or with age of donor (Fig. 3). All other markers tested did not appear to be expressed to any significant extent with melanocytes.

Novel expression of multiple markers for ROS and apoptosis in differentiating inner root sheath (IRS) of anagen scalp hair follicles. A striking feature of this study was the intense but highly nuanced expression of markers for ROS and apoptosis/(terminal) differentiation in the IRS (supplementary figures 3a-f), including Caspase-2 (CASP-2) and Caspase-9 (CASP-9), (supplementary figures 3a and 3b respectively), the DNA damage marker GADD45 (supplementary figure 3c), p21 (supplementary figure 3d), p57 and phospho-p57 (supplementary figure 3e), GR-1 (supplementary figure 3f.) and HO-1 (supplementary figures 3g and $3 \mathrm{~h}$ ). A component of the anti-oxidant glutathione metabolic pathway GR-1 was expressed predominantly in mature Henle's layer of the hair follicle IRS (supplementary figure 3f.). By contrast, the stress sensor GADD45 was detected within only early differentiating IRS cells (supplementary figure 3c), while the ROS-protective protein heme oxygenase-1 (HO-1) was intensely expressed in a small subset of IRS cells located usually in the upper follicle, at the level of the sebaceous gland, where IRS cornification is advanced to complete (supplementary figures $3 \mathrm{~g}$ and $3 \mathrm{~h}$ ). Variable expression of several markers was also detected elsewhere in the anagen HF as follows: dermal papilla (BCL-2, GP-1), hair follicle outer root sheath ORS (p53, p57 and phospho-p57), hair follicle pre-cortex (CASP-2, SOD-1, GADD45), hair bulb keratinocytes (GP-1, GADD45, 8-OHdG) and dermal sheath (CASP-2). Low levels of $\mathrm{p} 38 \alpha / \beta$ stress kinase were detected in early canities in two donors although it was 


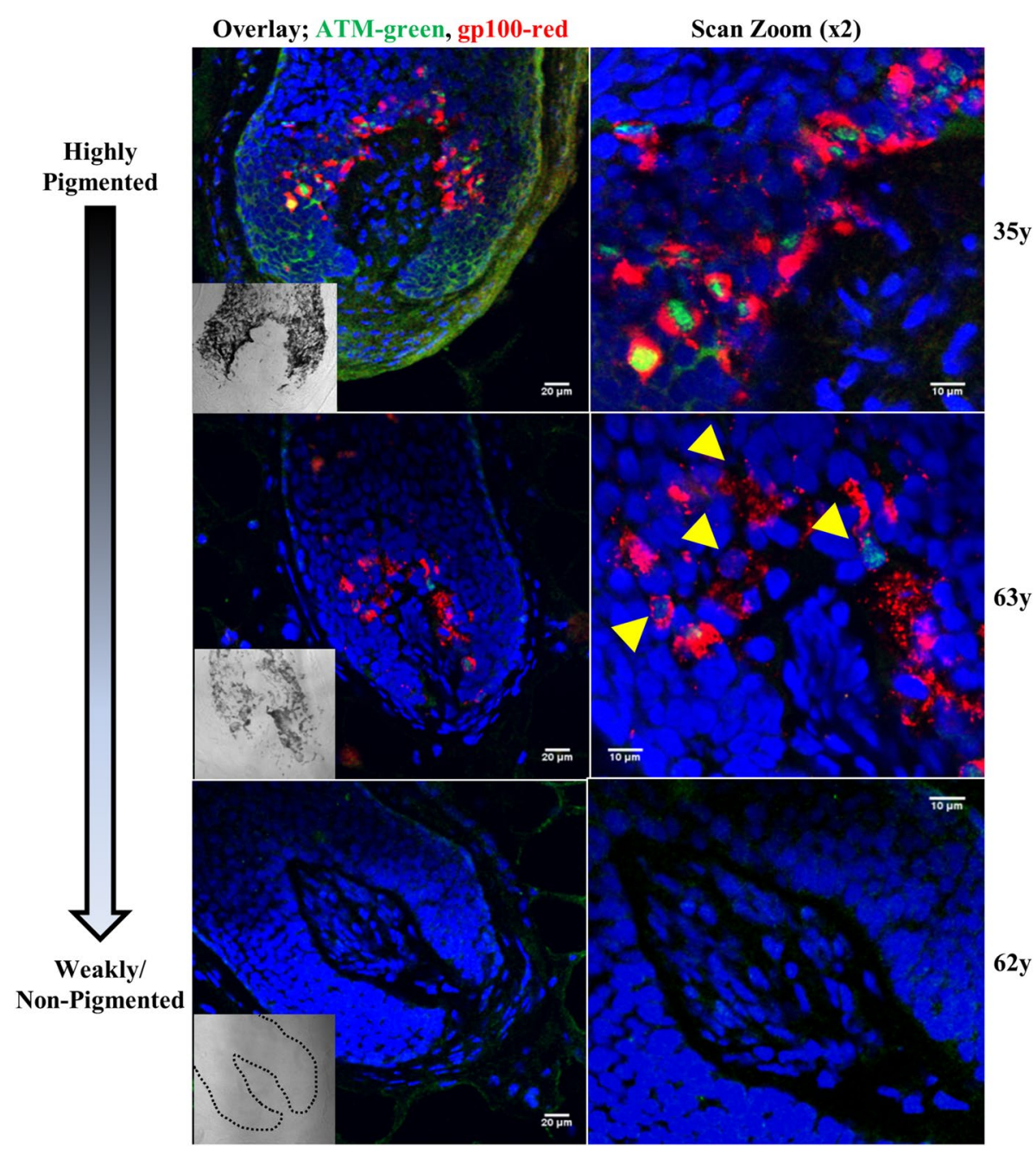

Figure 2. ATM is expressed within hair follicle bulbar melanocytes and correlates with pigmentation status. Overlays of ATM (green channel) and melanocyte marker GP100 (red channel) in adult human scalp showing strong and exclusive ATM expression in melanocytes within a pigmented follicle (top, 35-year old), less frequent ATM expression in a hair follicle with reduced pigmentation or mild canities (middle, 63-year old), and absent ATM expression in a grey (full canities) hair follicle (lower; 62-year old). Right panels show increased magnification $(\times 2)$ of the hair bulb melanocytes present in the central column. Yellow arrows indicate melanocytes with reduced or absent ATM expression in canities-affected scalp follicles. DAPI nuclear stain is shown in blue channel. Scale bar is shown on each image. Brightfield images of follicle pigmentation are shown in the inset image (follicle outline is indicated with black dashed line in 62-year old with full canities). Donor age is indicated on the right.

unclear if it was located within peripheral hair follicle melanocytes or in DP cells. We did not detect any CASP-3, phospho-p53, p27/phospho-p27 and phospho-p38 expression in these samples.

ATM protein levels increase in hair follicle melanocytes in vitro in response to elevated oxidative stress. In vitro analysis of primary hair follicle melanocytes (HFMs) isolated from scalp tissue showed strong nuclear expression of ATM (Fig. 4a). To investigate if ATM protein levels change in these melanocytes during elevated oxidative stress, these cells were treated with $40 \mu \mathrm{M} \mathrm{H}_{2} \mathrm{O}_{2}$ for $1 \mathrm{~h}$ to induce ROS. Protein levels of total ATM and the ROS-activated S1981-phosphorylated ATM were investigated using Western blot analysis. Results showed increased total ATM levels in HFMs after $\mathrm{H}_{2} \mathrm{O}_{2}$ treatment, and this increase was blocked by preincubation of HFMs with antioxidants VitE/Q for $1 \mathrm{~h}\left({ }^{*} p<0.05 \mathrm{VitE} / \mathrm{Q}\right.$ pretreatment versus untreated control; Fig. 4b,c). However, expression of ROS-activated phosphor-ATM S1981 could not be detected despite elevated levels of catalase in these cells in response to $\mathrm{H}_{2} \mathrm{O}_{2}$ treatment (Fig. 4d,e and supplementary figure 4).

Inhibition of ATM kinase activity in HFM in vitro reduces cell viability. To investigate if ATM activity influenced melanocyte survival under sustained elevated ROS conditions in culture we pre-treated cells with the ATM-specific kinase inhibitor KU60019 (which abrogates the kinase function of the protein and prevents downstream phosphorylation of ATM targets ${ }^{65}$ ) and incubated these cells with an increased concentration 


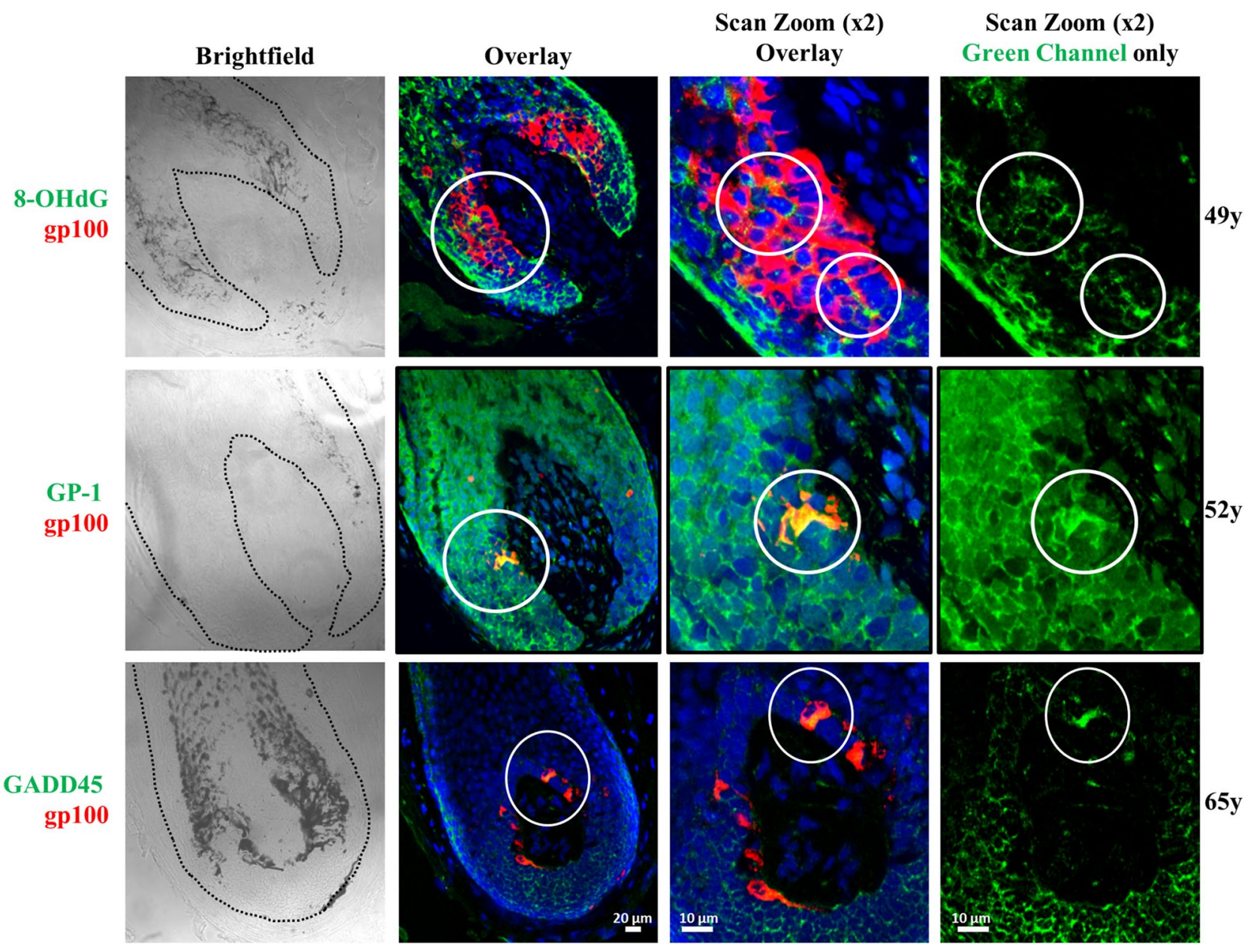

Figure 3. Colocalisation of 8-OHdG, GP-1 and GADD45 in occasional hair bulb melanocytes. Double IF staining in scalp tissue from 3 donors showing 8-OHdG (top; 49-year old), GP-1 (middle; 52-year old) or GADD45 (lower; 65-year old) expression in green channel colocalised with expression of the melanocyte marker GP100 (red channel). DAPI nuclear stain is shown in blue channel. Brightfield images on the left panels show the pigmentation status of each hair follicle (the follicle outline is indicated with a black dashed line). Right middle panels show increased magnification overlay $(\times 2)$ of the hair bulb regions. Far right panels show green channel staining only. Circles indicate increased protein expression in isolated melanocytes. Scale bar $=20 \mu \mathrm{m}$ for overlay images and $10 \mu \mathrm{m}$ for scan zoom $(\times 2)$ images.

of $250 \mu \mathrm{M} \mathrm{H}_{2} \mathrm{O}_{2}$ (to negate the effects of rapid $\mathrm{H}_{2} \mathrm{O}_{2}$ deactivation in vitro ensuring sustained elevated ROS during longer treatment times) and $100 \mu \mathrm{M}$ menadione (a naphthoquinone that can generate ROS through redox cycling $\left.^{66}\right)$ to raise ROS levels, for short $(1 \mathrm{~h})$ and long $(24 \mathrm{~h})$ durations then measured cell viability. As seen in Fig. 5, results showed that in the absence of ATM kinase activity, sustained $\mathrm{H}_{2} \mathrm{O}_{2}$ treatment for 24 h significantly reduced cell viability compared to controls $\left({ }^{* *} p<0.001\right.$ ANOVA). Treatment with the potent ROS inducer menadione ${ }^{67,68}$ also significantly reduced cell viability at both $1 \mathrm{~h}$ and $24 \mathrm{~h}$ time points compared to untreated controls $\left({ }^{* *} p<0.001\right.$ ANOVA). Treatment of HFM with only $5 \mu \mathrm{M}$ KU60019 was found to reduce total mean ATM protein levels compared to untreated cells (supplementary figure 5).

\section{Discussion}

Despite several studies into the biology and genetics of hair greying or canities, the mechanism by which human scalp hairs lose pigmentation remains poorly understood, due in part to the complexity of interaction between different cell types, complex protein interactions, differential gene expression during the hair growth cycle, and variable conditions that occur within the hair follicle microenvironment $t^{1,7-10,13,41,60,69-74}$. Here we have used a specific panel of antibodies chosen on the basis of their involvement in DNA repair, oxidative stress, cell cycle dynamics, senescence and apoptosis to investigate potential markers of canities within hair bulb melanocytes in the scalp of multiple normal healthy donors aged from 22 to 70 years old. One of the major findings of this study was that of all the biomarkers tested, only ATM was found to be exclusively expressed within hair bulb melanocytes and so correlated with hair follicle pigmentation status. ATM nuclear expression markedly decreased in the melanocytes of hair follicles with reduced pigmentation. ATM was also absent in some hair bulbs that contained few remaining GP100 positive melanocytes. 
a

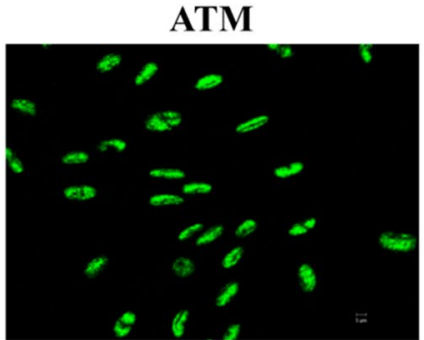

ATM/DAPI Overlay

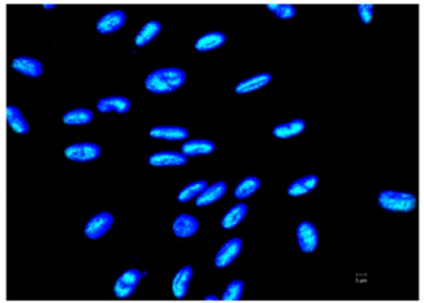

b

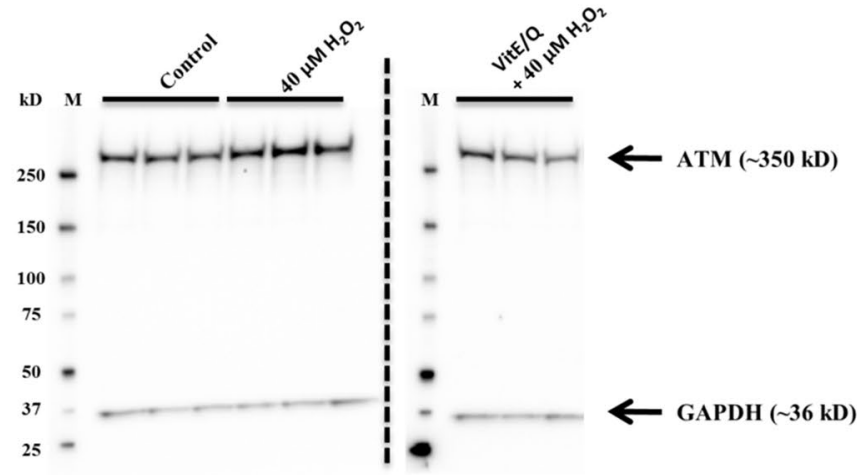

c

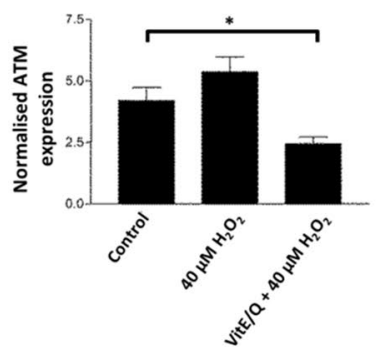

$* p<0.05$, ANOVA

d

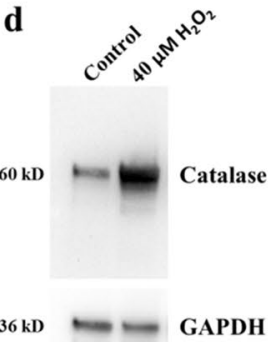

e

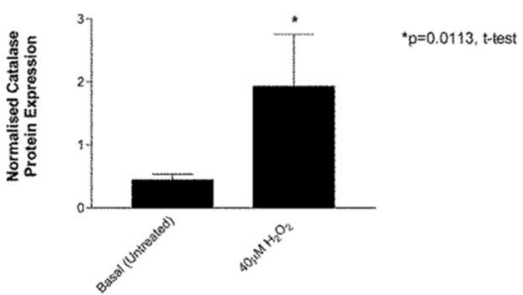

Figure 4. (a) ATM is expressed in HFM's in vitro. Immunocytochemistry staining showing the nuclear expression of ATM protein (green channel; left image) in cultured primary hair follicle melanocytes (from male scalp, 20-year old). DAPI nuclear stain (blue channel) is co-localised with nuclear ATM staining on the right-hand side image. Scale bars are shown on each image. (b) and (c) ATM expression is increased in HFM after exposure to oxidative stress and can be reduced by antioxidants. HFM were treated with $40 \mu \mathrm{M} \mathrm{H}_{2} \mathrm{O}_{2}$ for $1 \mathrm{~h}$ in parallel with untreated control cells and cells pre-treated for $1 \mathrm{~h}$ with the antioxidants VitE/Q prior to $\mathrm{H}_{2} \mathrm{O}_{2}$ addition. Levels of ATM protein expression $(\sim 350 \mathrm{kD})$ were assessed by Western blot (b). Antioxidant-treated samples were loaded on a second gel and processed in parallel with other samples under identical conditions. GAPDH $(\sim 36 \mathrm{kD})$ was used as a loading control. Marker is shown in the first lane of each gel $(\mathrm{M})$. An increase in ATM protein expression could be seen in $\mathrm{H}_{2} \mathrm{O}_{2}$ treated samples compared to control untreated cells (ns). Levels of ATM could be significantly decreased by preincubation with VitE/Q for $1 \mathrm{~h}$ before $\mathrm{H}_{2} \mathrm{O}_{2}$ treatment $\left({ }^{*} p<0.05\right.$ versus control, ANOVA; $n=3$ ). Graph in $\mathrm{c}$ shows quantification of mean ATM expression (normalised to GAPDH in relative densitometry units) from the Western blot. (d) and (e) Catalase expression is increased in HFMs after exposure to hydrogen peroxide.

Representative Western blot showing induction of catalase protein expression $(\sim 60 \mathrm{kD})$ in HFM's after treatment for $1 \mathrm{~h}$ with $40 \mu \mathrm{M}$ hydrogen peroxide. GAPDH $(36 \mathrm{kD})$ was used as a loading control. Graph in e shows quantification of mean catalase expression (normalised to GAPDH in relative densitometry units) from Western blots after $40 \mu \mathrm{M} \mathrm{H}_{2} \mathrm{O}_{2}$ treatment $(n=3)$. Unpaired t-test $\left({ }^{*} p=0.0113\right)$ compared $40 \mu \mathrm{M} \mathrm{H}_{2} \mathrm{O}_{2}$ treated cells versus controls. 

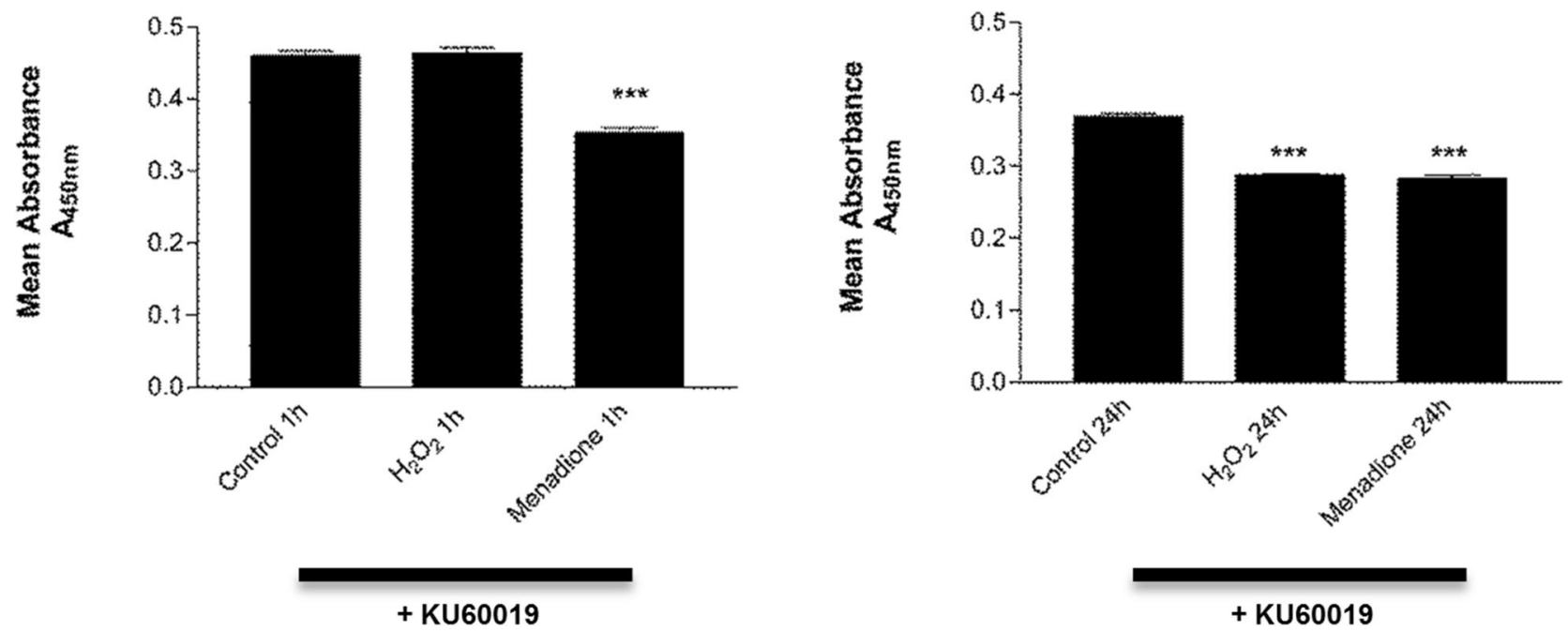

Figure 5. ATM kinase activity is necessary for cell survival and viability during sustained elevated oxidative stress. Melanocytes were pre-treated with the ATM specific kinase inhibitor KU60019 $(5 \mu \mathrm{M})$ for $1 \mathrm{~h}$ then incubated in either $250 \mu \mathrm{M} \mathrm{H}_{2} \mathrm{O}_{2}$ or $100 \mu \mathrm{M}$ Menadione (a known potent inducer of oxidative stress) for short $(1 \mathrm{~h})$ or long $(24 \mathrm{~h})$ time periods and cell viability assessed using the WST-1 assay $(\mathrm{n}=8)$ by measuring absorbance $\left(\mathrm{A}_{450 \mathrm{~nm}}\right)$ of mitochondrial generated formazan, the amount of which is directly proportional to the number of living cells. Left graph shows the results of $1 \mathrm{~h}$ treatments with each ROS inducer. Menadione treatments showed a significant reduction in cell viability ${ }^{* * *} p<0.001$, ANOVA) versus vehicle controls. Right graph shows the results of $24 \mathrm{~h}$ treatments with each ROS inducer. Both Menadione and $\mathrm{H}_{2} \mathrm{O}_{2}$ treatment significantly reduced cell viability $\left({ }^{* *} p<0.001\right.$, ANOVA) versus vehicle controls.

ATM is a PI3K-kinase and one of the major components of the DNA damage response (DDR) pathway ${ }^{46}$ but can also be activated during oxidative stress ${ }^{50,51}$. It exists as an active dimer ${ }^{45}$ and targets phosphorylation of downstream targets such as $\mathrm{CHK} 2, \gamma \mathrm{H} 2 \mathrm{AX}$ and $\mathrm{p} 53^{44,47-49}$. Investigations on primary hair follicle melanocytes (HFM) in vitro showed that total levels of ATM were upregulated after exposure to hydrogen peroxide that increased oxidative stress. Nishimura and colleagues showed that loss of ATM in melanoblast stem cells within the hair follicle bulge region in mice could sensitize the stem cells to genotoxic stress, leading to early differentiation, depletion from the niche and progressive hair greying over subsequent cell cycles due to eventual depletion of mature melanocytes from the hair bulb ${ }^{3,10}$. Oxidative stress is associated with the auto-phosphorylation of ATM at S1981 ${ }^{51}$, but this was not detected by Western blot analysis in the current study. Hydrogen peroxide is known to be a short-lived molecule in cell cultures that is degraded within $30 \mathrm{~min}$. However during that time it can be a potent activator of cellular anti-oxidant response systems, and if high enough can even induce DNA damage and cause cell death ${ }^{75}$. It has been speculated that when peroxide activates ATM in vitro little autophosphorylation takes place and it may be partially dependent on complexing with the MRN complex recruited to DNA repair ${ }^{51,76}$. This may explain why we could not detect ROS activated S1981 phosphorylation of ATM, particularly if the $\mathrm{H}_{2} \mathrm{O}_{2}$ concentrations were not high enough to induce DNA damage in HFMs. To determine if levels of ROS were increased during treatment's we measured catalase and GP-1 proteins levels by Western blot and both were markedly increased in HFM's after addition of $\mathrm{H}_{2} \mathrm{O}_{2}$ indicating that the ROS stress response within cells was active. If auto phosphorylation of ATM S1981 is absent and the antioxidant response is functioning in HFM then does ATM play a role in melanocyte survival during ROS induced stress? To investigate this we used the ATM specific kinase inhibitor KU60019 65 to inhibit the downstream phosphorylation activity of ATM with both $\mathrm{H}_{2} \mathrm{O}_{2}$ and menadione. The naphthoquinone menadione is metabolized by several enzymes through one electron reduction resulting in highly reactive unstable semiquinones ${ }^{77}$. These enter redox cycles to reform quinones but produce high amounts of free radical oxygen that are subsequently deactivated by dismutase's, producing elevated $\mathrm{H}_{2} \mathrm{O}_{2}^{67,68,77}$. We detected increased sensitivity to ROS and decreased cell viability in both cases, especially after a sustained increase in oxidative stress over $24 \mathrm{~h}$. This indicates that although ATM may not be activated through traditional ROS associated S1981 phosphorylation in HFM, functional ATM is still important to bulbar melanocyte survival during elevated oxidative stress. The exact mechanism by which ATM is activated by and which downstream proteins are targeted needs further investigation. Casual observation during treatments showed that HFM appeared to exhibit mild cytotoxicity effects to external $\mathrm{H}_{2} \mathrm{O}_{2}$ around the $250 \mathrm{uM}$ concentration and levels above this would produce mass cell death/apoptosis in cultures within $24 \mathrm{~h}$ of treatment. We postulate that functional melanocytes may have multiple intrinsic robust mechanisms to process $\mathrm{H}_{2} \mathrm{O}_{2}$ induced ROS due to the natural generation of $\mathrm{H}_{2} \mathrm{O}_{2}$ during melanogenesis itself, although further work is needed to investigate this. KU60019 has been well documented as a very potent ATM kinase inhibitor, used in multiple ATM publications at similar concentrations as our study. Thus, we would expect ATM activity to be completely suppressed ${ }^{78-86}$. Treatment of HFM with the KU60019 kinase inhibitor alone reduced total mean ATM protein levels compared to untreated cells. This would be expected as other studies have documented that ATM phosphorylation can increase total ATM expression through a feedback mechanism ${ }^{87-89}$. However, we cannot 
completely rule out secondary effects on closely related cell signalling pathways such as ATR/Chk1 mediated DNA repair which can in part be influenced by reductions in ATM kinase activity ${ }^{90,91}$.

In our study we only detected co-localisation and increased staining of three other proteins (GP-1, GADD45 and 8-OhDG) within bulbar melanocytes. Other protective mechanisms may cooperate with ATM expression/activity to protect bulbar melanocytes from oxidative stress-induced terminal differentiation similar to melanocyte stem cells within the murine hair follicle niche ${ }^{10}$. Kauser et al., showed that reduced expression of catalase in HFM cultured from elderly donors compared to HFM isolated from young donors, indicating that catalase expression/activity is an important effector in the response of melanocytes to aging-associated stimuli over time ${ }^{92}$. Other studies have shown the importance of the NRF2/HO-1 proteins in directing the ARE (antioxidant response elements) pathway in melanocytes in response to $\mathrm{H}_{2} \mathrm{O}_{2}$ induced stress ${ }^{41,42}$. Coincidently, ATM is thought to regulate selective mitochondrial functions through NRF1 (a similar protein of the NRF2 family) in response to $\mathrm{ROS}^{93}$. It has been shown that melanocytes can produce peroxide as a consequence of melanin synthesis ${ }^{25-28}$. Hair bulb melanocytes already have robust mechanisms in place using the cells own intrinsic antioxidant enzymes to reduce elevated ROS before critical levels that damage DNA occur. We would speculate that ATM is part of a larger cohort of proteins that are tightly regulated to cope with elevated ROS levels and that together they contribute to protecting melanocytes from oxidative stress and ensure their survival within the hair bulb. Changes in expression levels of these marker proteins could imbalance ROS levels, leading to a gradual reduction in melanocyte protection and viability over time leading to hair greying. As loss of ATM correlates with decreased pigmentation in hair follicle melanocytes it is difficult to determine if loss of melanin contributes to a reduction in ATM expression or drives the process of ATM loss more rapidly. Melanin production is known to decrease and become less efficient with aging in melanocytes, with fewer melanosomes produced and poor quality/quantity of melanin ${ }^{8,71}$. We also specifically analysed scalp tissue from skin types II-III in this study and so could not detect differences between eumelanotic and phaeomelanotic phenotypes. Further work is therefore needed to investigate this.

Elsewhere in the hair follicle, several other cell cycle, DDR, apoptosis and ROS metabolising anti-oxidant markers appear to have very specific expression in specialised cell layers of the hair follicle, particularly those cells undergoing differentiation in the anagen-specific IRS during hair fibre formation. Different compartments or cell layers of the hair follicle may have their own individual 'microenvironment', with varied requirements to protect cells from ROS caused by normal cell activity such as differentiation. Lemasters et al., showed that hair follicles have specific compartments of mitochondrial gradients and oxidative metabolism, which leads to increased ROS during the development of the hair shaft that they termed a 'ring of fire ${ }^{94}$. Another study showed that mice with a keratinocyte-specific deficiency in mitochondrial transcription factor A (TFAM), a gene required for the transcription of mitochondrial genes, have abnormalities in hair follicle growth, and that mitochondriagenerated ROS was in fact necessary for the mediation of cell differentiation ${ }^{95}$. Indeed, a high proportion of the markers tested in our study localised to where cells differentiate to establish the IRS, and it appears their presence is necessary to prevent damage or to stabilise ROS in cells during the differentiation process. Further studies are needed to determine if regulated expression of p21, CASP-2, CASP-9, SOD-1 and HO-1, components of the anti-oxidant glutathione metabolic pathway GP-1 and GR-1, and the DNA damage marker GADD45 are necessary to complete differentiation in specialised keratinocyte layers.

In summary we have shown that ATM protein expression correlates with pigmentation status in greying hair follicles and contributes to sustained melanocyte viability in vitro during elevated ROS levels. We have also showed that other markers of DNA damage/cell cycle (p21, p53, p57 and phospho-p57, GADD45, 8-OHdG), apoptotic (BCL-2, CASP-2, CASP-9) and anti-oxidant pathways (GP-1, SOD-1, HO-1, p38 stress kinase), that are not specifically associated with hair follicle pigmentation, have distinct expression patterns and colocalise to parts of the hair follicle such as the IRS, ORS, DP and cortex. These results highlight the multicellular complexity of the hair follicle to cope with oxidative stress and indicate novel previously unreported roles for several proteins implicated in cell cycle/senescence and oxidative stress in IRS differentiation pathways and hair follicle growth. Further work is needed to establish how ATM and other proteins co-operate to reduce damage to the hair follicle caused by the regular cellular processes during hair growth and/or pigmentation and the external factor associated with the chronological aging/greying process.

Received: 10 February 2020; Accepted: 12 October 2020

Published online: 30 October 2020

\section{References}

1. Choi, H. I. et al. Hair greying is associated with active hair growth. Br. J. Dermatol. 165(6), 1183-1189 (2011).

2. Slominski, A. et al. Melanogenesis during the anagen-catagen-telogen transformation of the murine hair cycle. J. Invest. Dermatol. 102(6), 862-869 (1994).

3. Nishimura, E. K. Melanocyte stem cells: a melanocyte reservoir in hair follicles for hair and skin pigmentation. Pigment Cell Melanoma Res. 24(3), 401-410 (2011).

4. Nishimura, E. K., Granter, S. R. \& Fisher, D. E. Mechanisms of hair graying: incomplete melanocyte stem cell maintenance in the niche. Science 307(5710), 720-724 (2005).

5. Nishimura, E. K. et al. Dominant role of the niche in melanocyte stem-cell fate determination. Nature 416(6883), 854-860 (2002).

6. Nishimura, E. K. et al. Key roles for transforming growth factor beta in melanocyte stem cell maintenance. Cell Stem Cell 6(2), $130-140$ (2010).

7. Tobin, D. J. The cell biology of human hair follicle pigmentation. Pigment Cell Melanoma Res. 24(1), 75-88 (2011).

8. Tobin, D. J. Age-related hair pigment loss. Curr. Probl. Dermatol. 47, 128-138 (2015).

9. Shi, Y. et al. Premature graying as a consequence of compromised antioxidant activity in hair bulb melanocytes and their precursors. PLoS ONE 9(4), e93589 (2014). 
10. Inomata, K. et al. Genotoxic stress abrogates renewal of melanocyte stem cells by triggering their differentiation. Cell 137(6), 1088-1099 (2009).

11. Tobin, D. J. et al. Do hair bulb melanocytes undergo apoptosis during hair follicle regression (catagen)?. J. Invest. Dermatol. 111(6), 941-947 (1998).

12. Yu, M. et al. Deficiency in nucleotide excision repair family gene activity, especially ERCC3, is associated with non-pigmented hair fiber growth. PLoS ONE 7(5), e34185 (2012).

13. O'Sullivan, J. D. B., et al. The biology of human hair graying. Biol Rev Camb Philos Soc. https://doi.org/10.1111/brv.12648 (2020).

14. Dean, R. T. et al. Biochemistry and pathology of radical-mediated protein oxidation. Biochem. J. 324 (Pt 1), 1-18 (1997).

15. Fu, S. L. \& Dean, R. T. Structural characterization of the products of hydroxyl-radical damage to leucine and their detection on proteins. Biochem. J. 324(Pt 1), 41-48 (1997).

16. Pero, R. W. et al. Oxidative stress induces DNA damage and inhibits the repair of DNA lesions induced by N-acetoxy-2-acetylaminofluorene in human peripheral mononuclear leukocytes. Cancer Res. 50(15), 4619-4625 (1990).

17. Jones, D. P. \& Sies, H. The redox code. Antioxid. Redox Signal 23(9), 734-746 (2015).

18. Adelman, R., Saul, R. L. \& Ames, B. N. Oxidative damage to DNA: relation to species metabolic rate and life span. Proc. Natl. Acad. Sci. USA 85(8), 2706-2708 (1988).

19. Yan, S. D. et al. Glycated tau protein in Alzheimer disease: a mechanism for induction of oxidant stress. Proc. Natl. Acad. Sci. USA 91(16), 7787-7791 (1994).

20. Yan, S. D. et al. Non-enzymatically glycated tau in Alzheimer's disease induces neuronal oxidant stress resulting in cytokine gene expression and release of amyloid beta-peptide. Nat. Med. 1(7), 693-699 (1995).

21. Justice, A. E. et al. Genome-wide meta-analysis of 241,258 adults accounting for smoking behaviour identifies novel loci for obesity traits. Nat. Commun. 8, 14977 (2017).

22. Lee, J. D. et al. The role of biomarkers of oxidative stress in breast cancer risk and prognosis: a systematic review of the epidemiologic literature. J. Womens Health (Larchmt) 26(5), 467-482 (2017).

23. Ngo, H. K. C. et al. Nrf2 mutagenic activation drives hepatocarcinogenesis. Cancer Res. 77, 4797-4808 (2017).

24. Marionnet, C. et al. Modulation of gene expression induced in human epidermis by environmental stress in vivo. J. Invest. Dermatol. 121(6), 1447-1458 (2003).

25. Felix, C. C. et al. Melanin photoreactions in aerated media: electron spin resonance evidence for production of superoxide and hydrogen peroxide. Biochem. Biophys. Res. Commun. 84(2), 335-341 (1978).

26. Felix, C. C., Hyde, J. S. \& Sealy, R. C. Photoreactions of melanin: a new transient species and evidence for triplet state involvement. Biochem. Biophys. Res. Commun. 88(2), 456-461 (1979).

27. Noonan, F. P. et al. Melanoma induction by ultraviolet A but not ultraviolet B radiation requires melanin pigment. Nat. Commun. 3, 884 (2012).

28. Denat, L. et al. Melanocytes as instigators and victims of oxidative stress. J. Invest. Dermatol. 134(6), 1512-1518 (2014).

29. Marrot, L. et al. Molecular responses to stress induced in normal human caucasian melanocytes in culture by exposure to simulated solar UV. Photochem. Photobiol. 81(2), 367-375 (2005).

30. Marrot, L. et al. The significance of Nrf2 pathway in (photo)-oxidative stress response in melanocytes and keratinocytes of the human epidermis. Pigment Cell Melanoma Res. 21(1), 79-88 (2008).

31. Jian, Z. et al. Heme oxygenase-1 protects human melanocytes from $\mathrm{H} 2 \mathrm{O} 2$-induced oxidative stress via the Nrf2-ARE pathway. J. Invest. Dermatol. 131(7), 1420-1427 (2011).

32. Tsang, C. K. et al. Superoxide dismutase 1 acts as a nuclear transcription factor to regulate oxidative stress resistance. Nat. Commun. 5, 3446 (2014).

33. Espinosa-Diez, C. et al. Antioxidant responses and cellular adjustments to oxidative stress. Redox Biol. 6, 183-197 (2015).

34. Itoh, K. et al. Keap1 represses nuclear activation of antioxidant responsive elements by Nrf2 through binding to the amino-terminal Neh2 domain. Genes Dev. 13(1), 76-86 (1999).

35. Itoh, K. et al. Emerging functional cross-talk between the Keap1-Nrf2 system and mitochondria. J. Clin. Biochem. Nutr. 56(2), 91-97 (2015).

36. Venugopal, R. \& Jaiswal, A. K. Nrf2 and Nrf1 in association with Jun proteins regulate antioxidant response element-mediated expression and coordinated induction of genes encoding detoxifying enzymes. Oncogene 17(24), 3145-3156 (1998).

37. Li, N. et al. Nrf2 is a key transcription factor that regulates antioxidant defense in macrophages and epithelial cells: protecting against the proinflammatory and oxidizing effects of diesel exhaust chemicals. J. Immunol. 173(5), 3467-3481 (2004).

38. Ishii, T. et al. Transcription factor Nrf2 coordinately regulates a group of oxidative stress-inducible genes in macrophages. J. Biol. Chem. 275(21), 16023-16029 (2000).

39. Li, Y. \& Jaiswal, A. K. Regulation of human $\mathrm{NAD}(\mathrm{P}) \mathrm{H}$ :quinone oxidoreductase gene. Role of AP1 binding site contained within human antioxidant response element. J. Biol. Chem. 267(21), 15097-104 (1992).

40. Itoh, K. et al. An Nrf2/small Maf heterodimer mediates the induction of phase II detoxifying enzyme genes through antioxidant response elements. Biochem. Biophys. Res. Commun. 236(2), 313-322 (1997).

41. Jian, Z. et al. Impaired activation of the Nrf2-ARE signaling pathway undermines $\mathrm{H}_{2} \mathrm{O}_{2}$-induced oxidative stress response: a possible mechanism for melanocyte degeneration in vitiligo. J. Invest. Dermatol. 134(8), 2221-2230 (2014).

42. Haslam, I. S. et al. Oxidative damage control in a human (Mini-) organ: Nrf2 activation protects against oxidative stress-induced hair growth inhibition. J. Invest. Dermatol. 137(2), 295-304 (2017).

43. Cadet, J., Douki, T. \& Ravanat, J. L. Oxidatively generated damage to cellular DNA by UVB and UVA radiation. Photochem. Photobiol. 91(1), 140-155 (2015).

44. Matsuoka, S. et al. ATM and ATR substrate analysis reveals extensive protein networks responsive to DNA damage. Science 316(5828), 1160-1166 (2007).

45. Bakkenist, C. J. \& Kastan, M. B. DNA damage activates ATM through intermolecular autophosphorylation and dimer dissociation. Nature 421(6922), 499-506 (2003).

46. Lee, J. H. \& Paull, T. T. Direct activation of the ATM protein kinase by the Mre11/Rad50/Nbs1 complex. Science 304(5667), 93-96 (2004).

47. Craig, A. L. et al. DeltaNp63 transcriptionally regulates ATM to control p53 Serine-15 phosphorylation. Mol. Cancer 9, 195 (2010).

48. Burma, S. et al. ATM phosphorylates histone H2AX in response to DNA double-strand breaks. J. Biol. Chem. 276(45), 42462-42467 (2001).

49. Smith, J. et al. The ATM-Chk2 and ATR-Chk1 pathways in DNA damage signaling and cancer. Adv. Cancer Res. 108, 73-112 (2010).

50. Guo, Z., Deshpande, R. \& Paull, T. T. ATM activation in the presence of oxidative stress. Cell Cycle 9(24), 4805-4811 (2010).

51. Guo, Z. et al. ATM activation by oxidative stress. Science 330(6003), 517-521 (2010).

52. Watters, D. et al. Localization of a portion of extranuclear ATM to peroxisomes. J. Biol. Chem. 274(48), 34277-34282 (1999).

53. Zhang, J. et al. ATM functions at the peroxisome to induce pexophagy in response to ROS. Nat. Cell Biol. 17(10), 1259-1269 (2015).

54. Watters, D. et al. Cellular localisation of the ataxia-telangiectasia (ATM) gene product and discrimination between mutated and normal forms. Oncogene 14(16), 1911-1921 (1997).

55. Boder, E. \& Sedgwick, R. P. Ataxia-telangiectasia; a familial syndrome of progressive cerebellar ataxia, oculocutaneous telangiectasia and frequent pulmonary infection. Pediatrics 21(4), 526-554 (1958). 
56. Boder, E. \& Sedgwick, R. P. Ataxia-telangiectasia. A review of 101 cases. Little Club Clin. Dev. Med. 8, 110-118 (1963).

57. Corti, A. et al. DNA damage and transcriptional regulation in iPSC-derived neurons from Ataxia Telangiectasia patients. Sci. Rep. 9(1), 651 (2019).

58. Barlow, C. et al. Loss of the ataxia-telangiectasia gene product causes oxidative damage in target organs. Proc. Natl. Acad. Sci. USA 96(17), 9915-9919 (1999).

59. Hibma, J. C. et al. A novel phenotypic marker for ATM-deficient 129S6/SvEvTac-ATMtm1Awb/J mice. Anat. Rec. (Hoboken) 290(3), 243-250 (2007).

60. Arck, P. C. et al. Towards a "free radical theory of graying": melanocyte apoptosis in the aging human hair follicle is an indicator of oxidative stress induced tissue damage. FASEB J. 20(9), 1567-1569 (2006).

61. Gruber, J. V. et al. In vitro and ex vivo examination of topical Pomiferin treatments. Fitoterapia 94, 164-171 (2014).

62. Tobin, D. J., Colen, S. R. \& Bystryn, J. C. Isolation and long-term culture of human hair-follicle melanocytes. J. Invest. Dermatol. 104(1), 86-89 (1995).

63. Kauser, S. et al. Modulation of the human hair follicle pigmentary unit by corticotropin-releasing hormone and urocortin peptides. FASEB J. 20(7), 882-895 (2006).

64. Commo, S. et al. Absence of TRP-2 in melanogenic melanocytes of human hair. Pigment Cell Res. 17(5), 488-497 (2004).

65. Golding, S. E. et al. Improved ATM kinase inhibitor KU-60019 radiosensitizes glioma cells, compromises insulin, AKT and ERK prosurvival signaling, and inhibits migration and invasion. Mol. Cancer Ther. 8(10), 2894-2902 (2009).

66. Chuang, Y. Y. et al. Gene expression after treatment with hydrogen peroxide, menadione, or t-butyl hydroperoxide in breast cancer cells. Cancer Res. 62(21), 6246-6254 (2002).

67. Cojocel, C., Novotny, L. \& Vachalkova, A. Mutagenic and carcinogenic potential of menadione. Neoplasma 53(4), 316-323 (2006).

68. Thor, H. et al. The metabolism of menadione (2-methyl-1,4-naphthoquinone) by isolated hepatocytes. A study of the implications of oxidative stress in intact cells. J. Biol. Chem. 257(20), 12419-25 (1982).

69. Jadkauskaite, L. et al. Oxidative stress management in the hair follicle: could targeting NRF2 counter age-related hair disorders and beyond?. Bioessays 39(8), 1700029 (2017).

70. Peters, E. M., Imfeld, D. \& Graub, R. Graying of the human hair follicle. J. Cosmet. Sci. 62(2), 121-125 (2011).

71. Tobin, D. J. Aging of the hair follicle pigmentation system. Int. J. Trichol. 1(2), 83-93 (2009).

72. Tobin, D. J. et al. The fate of hair follicle melanocytes during the hair growth cycle. J. Investig. Dermatol. Symp. Proc. 4(3), 323-332 (1999).

73. Van Neste, D. \& Tobin, D. J. Hair cycle and hair pigmentation: dynamic interactions and changes associated with aging. Micron 35(3), 193-200 (2004).

74. Wood, J. M. et al. Senile hair graying: $\mathrm{H}_{2} \mathrm{O}_{2}$-mediated oxidative stress affects human hair color by blunting methionine sulfoxide repair. FASEB J. 23(7), 2065-2075 (2009).

75. Gulden, M. et al. Cytotoxic potency of $\mathrm{H} 2 \mathrm{O} 2$ in cell cultures: impact of cell concentration and exposure time. Free Radic. Biol. Med. 49(8), 1298-1305 (2010).

76. Paull, T. T. Mechanisms of ATM activation. Annu. Rev. Biochem. 84, 711-738 (2015).

77. Iyanagi, T. \& Yamazaki, I. One-electron-transfer reactions in biochemical systems. V. Difference in the mechanism of quinone reduction by the NADH dehydrogenase and the NAD(P)H dehydrogenase (DT-diaphorase). Biochim. Biophys. Acta 216(2), 282-94 (1970).

78. Zhao, J. et al. ATM deficiency accelerates DNA damage, telomere erosion, and premature T cell aging in HIV-infected individuals on antiretroviral therapy. Front. Immunol. 10, 2531 (2019).

79. Blignaut, M. et al. Ataxia-Telangiectasia Mutated is located in cardiac mitochondria and impacts oxidative phosphorylation. Sci. Rep. 9(1), 4782 (2019).

80. Nakada, Y. et al. DNA damage response mediates pressure overload-induced cardiomyocyte hypertrophy. Circulation 139(9), 1237-1239 (2019).

81. Ivanov, V. N. et al. Inhibition of ATM kinase upregulates levels of cell death induced by cannabidiol and gamma-irradiation in human glioblastoma cells. Oncotarget 10(8), 825-846 (2019).

82. Lang, L. et al. ATM-mediated phosphorylation of cortactin involved in actin polymerization promotes breast cancer cells migration and invasion. Cell Physiol. Biochem. 51(6), 2972-2988 (2018).

83. Hu, F. et al. Ataxia-Telangiectasia Mutated (ATM) protein signaling participates in development of pulmonary arterial hypertension in rats. Med. Sci. Monit. 23, 4391-4400 (2017).

84. Beumer, J. H. et al. Functional analyses of ATM, ATR and Fanconi anemia proteins in lung carcinoma: ATM, ATR and FA in lung carcinoma. BMC Cancer 15, 649 (2015).

85. Zhu, Y. et al. Improved ataxia telangiectasia mutated kinase inhibitor KU60019 provides a promising treatment strategy for noninvasive breast cancer. Oncol. Lett. 8(5), 2043-2048 (2014).

86. Vecchio, D. et al. Pharmacokinetics, pharmacodynamics and efficacy on pediatric tumors of the glioma radiosensitizer KU60019. Int. J. Cancer 136(6), 1445-1457 (2015).

87. Di Virgilio, M., Ying, C. Y. \& Gautier, J. PIKK-dependent phosphorylation of Mre11 induces MRN complex inactivation by disassembly from chromatin. DNA Repair (Amst) 8(11), 1311-1320 (2009).

88. Lim, D. S. et al. ATM phosphorylates p95/nbs1 in an S-phase checkpoint pathway. Nature 404(6778), 613-617 (2000).

89. Gatei, M. et al. ATM protein-dependent phosphorylation of Rad50 protein regulates DNA repair and cell cycle control. J. Biol. Chem. 286(36), 31542-31556 (2011).

90. Doksani, Y. et al. Replicon dynamics, dormant origin firing, and terminal fork integrity after double-strand break formation. Cell 137(2), 247-258 (2009).

91. Jazayeri, A. et al. ATM- and cell cycle-dependent regulation of ATR in response to DNA double-strand breaks. Nat. Cell Biol. 8(1), 37-45 (2006).

92. Kauser, S. et al. Human hair follicle and epidermal melanocytes exhibit striking differences in their aging profile which involves catalase. J. Invest. Dermatol. 131(4), 979-982 (2011).

93. Chow, H. M. et al. ATM is activated by ATP depletion and modulates mitochondrial function through NRF1. J. Cell Biol. 218, 909-928 (2019).

94. Lemasters, J. J. et al. Compartmentation of mitochondrial and oxidative metabolism in growing hair follicles: a ring of fire. J. Invest. Dermatol. 137(7), 1434-1444 (2017).

95. Hamanaka, R. B. et al. Mitochondrial reactive oxygen species promote epidermal differentiation and hair follicle development. Sci. Signal. 6(261), 8ra8 (2013).

\section{Acknowledgements}

This work was supported by funding to DJT by BASF Beauty Care Solutions, France. 


\section{Author contributions}

S.K.S. was responsible for the acquisition, analysis, interpretation of data, and with D.J.T. wrote the manuscript and prepared all the figures. S.K.S., S.M., O.F., L.D. and D.J.T. assisted with conception of the work, interpretation of the data and reviewed the manuscript.

\section{Competing interests}

The authors declare no competing interests.

\section{Additional information}

Supplementary information is available for this paper at https://doi.org/10.1038/s41598-020-75334-9.

Correspondence and requests for materials should be addressed to S.K.S. or D.J.T.

Reprints and permissions information is available at www.nature.com/reprints.

Publisher's note Springer Nature remains neutral with regard to jurisdictional claims in published maps and institutional affiliations.

(c) (i) Open Access This article is licensed under a Creative Commons Attribution 4.0 International License, which permits use, sharing, adaptation, distribution and reproduction in any medium or format, as long as you give appropriate credit to the original author(s) and the source, provide a link to the Creative Commons licence, and indicate if changes were made. The images or other third party material in this article are included in the article's Creative Commons licence, unless indicated otherwise in a credit line to the material. If material is not included in the article's Creative Commons licence and your intended use is not permitted by statutory regulation or exceeds the permitted use, you will need to obtain permission directly from the copyright holder. To view a copy of this licence, visit http://creativecommons.org/licenses/by/4.0/.

(C) The Author(s) 2020 